\title{
Revelación de homosexualidad de un hijo y reconstrucción del vínculo parento-filial $^{1}$
}

\author{
Miguel Arévalo Contreras* \\ Carolina Lizama Truán** \\ Lilian Sanhueza Díaz***
}

RESUMEN

Para las familias occidentales, la identidad heterosexual de los hijos no reviste la necesidad de redefinir la identidad de rol ni por ende la relación familiar, toda vez que es una identidad sexual legitimada socialmente. Sin embargo, en el caso de jóvenes que manifiestan una identidad homosexual, la relación con la figura parental suele atravesar un proceso de reconstrucción de dicha relación y de los roles asignados culturalmente, en el marco del reconocimiento a una opción de vida distinta a la que los padres esperaban para sus hijos. En este artículo se presentan los resultados de un estudio de caso, realizado en la Región de la Araucanía, a partir del cual se describen los procesos de reconstrucción de la relación parento-filial, desde la perspectiva de adultos que desempeñan un rol parental, ante la revelación de homosexualidad de los hijos.

Palabras clave: Identidad homosexual - relación parento-filial - secreto familiar.

\section{Revelação de homosexualidad de um filho e reconstrução do vínculo parento-filial}

\section{RESUMO}

Para as famílias ocidentais, a identidade heterossexual das crianças não tem a necessidade de redefinir a identidade papel e, portanto, a relação familiar, já que é uma identidade social legítima sexual. No entanto, no caso dos jovens que expressam uma identidade homossexual, a relação com a figura dos pais é geralmente através de um processo de reconstrução do relacionamento e papéis culturalmente atribuídos no âmbito do

1 Estudio realizado en el marco de la Tesis para optar al grado de Licenciado en Trabajo Social, por los estudiantes Miguel Arévalo, Carolina Lizama y Paula Valdivia. Tesis guiada por la docente Mg. Lilian Sanhueza Díaz, adscrita al Departamento de Trabajo Social de la Universidad Católica de Temuco.

* Chileno. Trabajador Social. Egresado Universidad Católica de Temuco. Correo electrónico: mearevalo@uc.cl

** Chilena. Trabajadora Social. Egresada Universidad Católica de Temuco. Correo electrónico: carolina.lizama.truan@gmail.com

*** Chilena. Trabajadora Social. Magíster en Intervención Social. Docente. Universidad Católica de Temuco. Correo electrónico: Isanhueza@uctemuco.cl. 
reconhecimento de um modo de vida diferente da que pais esperavam seus filhos. Neste artigo apresentamos os resultados de estudos de caso realizados na região Araucania, a partir do qual descreve o processo de reconstrução da relação pai-filho a partir da perspectiva dos adultos que desempenham um papel parental, divulgação da homossexualidade para as crianças.

Palavras chave: Identidade homossexual - relacionamento empresa-mãe segredo de família.

\section{Disclosure of homosexuality of a child and reconstruction of the parent-child bond}

\section{ABSTRACT}

For Western families, heterosexual identity for children does not have the need to redefine the role or identity thus the family relationship, since it is a socially legitimate sexual identity. However, in the case of young people who display a gay identity, relationships with parental figure usually goes through a process of reconstruction in this relationship and the culturally assigned roles in the context of recognition from a choice of life different from that parents expected their children. In this article we present the results from Case Studies, conducted in the region of Araucanía, after which describes the processes of reconstruction of the parent-child relationship from the perspective of adults who play a parental role, to the revelation of homosexuality of their children.

Key words: Homosexual identity - parento-affiliated relation - family secret. 


\section{Antecedentes}

La familia es el referente primario que permite a los actores sociales acceder al mundo social; elaborar significaciones, símbolos y construcciones acerca de diversos aspectos que inundan y dan sentido a la vida humana, entre ellos la identidad sexual (Herrera; 2007). De este modo cada persona construye una idea del mundo y de sí misma, anclada en procesos internos subjetivos que se articulan estrechamente con elementos del mundo social, a través de una relación intersubjetiva con actores de dicho mundo (Schutz; 1993).

La revelación de la identidad homosexual de jóvenes² que cumplen un rol filial ante adultos ${ }^{3}$ que desempeñan un rol parental, es una situación específica de una relación afectivo-emocional significativa entre estos actores, que a su vez se traduce en un proceso de construcción de significados acerca de la identidad de roles esperados mutuamente por ambos. Dicho proceso "se refiere a la práctica de crear y modificar roles para hacerlos más explícitos" (Iturrieta; 2001: 12). Esto da cuenta por una parte, de que existen aspectos de los roles que son "más estáticos", que se ligan a la "asunción de roles" y que se caracterizan por ser conductas preestablecidas definidas a nivel social; y por otra parte, aspectos de los roles que poseen un carácter "más dinámico", que se vinculan con la "creación de roles" refiriéndose a aquellos que son elaborados a partir de situaciones específicas que generan modificación y explicitación de éstos.

Se aborda la construcción de significados acerca de la identidad de rol esperado por los adultos, a partir de los supuestos teóricos del interaccionismo simbólico, desde el cual se afirma que: "cada persona se relaciona con otra, a partir de los símbolos con los que esa persona interpreta el mundo cotidiano en que vive, y también desde las expectativas que piensa que las otras personas tienen respecto a ella" (Iturrieta; 2001: 5). Así, se reconoce la influencia del medio social en esta construcción de identidad de rol, tal como lo señala Goffman (1998): "sea que interactuemos con extraños o con amigos intimos, descubriremos que las huellas de la sociedad quedan claramente impresas en estos contactos" (Goffman 1998: 69).

2 En adelante se le denominará "jóvenes", a aquellos jóvenes que desempeñan un rol filial y que han revelado su identidad homosexual a su figura parental.

3 En adelante se le denominará "adultos" a aquellos adultos que cumplen un rol parental, entendiendo que el rol parental puede ser ejercido por padres, abuelos u otros significativos. 
Cuando nos referimos a una identidad sexual, sea esta heterosexual, homosexual, bisexual u otra, lo hacemos desde la perspectiva del interaccionismo simbólico. En este sentido, no entendemos la identidad sexual como algo estático y permanente, sino más bien como un proceso de construcción simbólica.

Para la cultura occidental del sigloXXI, parentalidad y conyugalidad son los ejes relacionales constitutivos de la familia, por esencia. Linares (2002) hace referencia a la parentalidad como una relación eminentemente complementaria: "los hijos tienen que ser preparados por los padres para integrarse armoniosamente en la sociedad, aprendiendo tanto a respetar sus normas como a protegerse adecuadamente" (Linares 2002: 35), asignando por tanto, funciones de socialización y protección a las figuras parentales, planteamiento que coincide con el de otros autores (Martin 2002; Montejo 2000).

Respecto de la homosexualidad, Pérez (2005) dice que "no tiene que ver solamente con la sexualidad y más en concreto con el deseo sexual y las prácticas sexuales (...) sino que tiene que ver de una forma profunda con la filiación humana, con el parentesco, con el deseo y la necesidad de establecer relaciones de pareja comprometidas (Pérez 2005: 22), así es como la definición de una identidad homosexual y su consiguiente reconocimiento público frente a la figura parental atraviesa en una primera etapa por la configuración del secreto (Pincus E Dare; 1982). A este respecto, Pérez (2005) señala que los secretos "crean una atmósfera de seguridad provisional, pero cuando finalmente caduca su utilidad práctica, tiranizan a los que originalmente habían protegido" (Pérez 2005: 73), originándose relaciones entre adultos y jóvenes que facilitan la creación de contextos familiares en los que se desconocen situaciones, manteniéndose en el tiempo esta información oculta.

Las formas de actuar frente a una situación, implica compartir símbolos dentro de lo que se denomina universo simbólico, el cual "se concibe como la matriz de todos los significados objetivados socialmente y subjetivamente reales" (Berger y Luckmann 1994: 125). El universo simbólico que comparte una familia, se llama también conjunto de significados. Dicho conjunto, es lo que la familia puede concebir como formas de actuar e interactuar frente a distintas situaciones, como es la revelación de la identidad homosexual de uno de sus integrantes, y por tanto, esas formas de actuar dependerán en gran medida del universo simbólico que comparte 
la familia y que se manifiesta en la forma en que ésta procesará la información referente a la situación.

\section{Identidad social real e identidad social virtual: Estigma y descrédito}

El concepto de identidad social, alude a ciertos atributos que un sujeto posee dentro del "mundo social"; éstos permiten predecir en qué categoría se encuentra dicho sujeto. Por consiguiente, "es posible que al encontrarnos frente a un extraño las primeras apariencias nos permitan prever en quécategoría se halla y cuáles son sus atributos" (Goffman; 1998: 12). Por lo tanto, las personas en la vida social se apoyan en características que poseen otros sujetos, transformándolas en "expectativas normativas" que contribuyen a establecer "clases" de sujetos en la realidad social.

Dentro de las "expectativas normativas", encontramos ciertos supuestos que se forman en el "imaginario social" con respecto a los atributos que asignamos constantemente a ciertos sujetos. Estos atributos son parte de una gama de características que se le atribuyen a las personas; características que pasan a formar el carácter que se le imputa a un sujeto, "una caracterización 'en esencia', una identidad social virtual" (Goffman; 1998: 12). No obstante, se encuentra otra categoría y atributos que son demostrables de hecho en la experiencia, que por tanto le pertenecen real y evidentemente a un sujeto, lo que se denomina "identidad social real", sin embargo, "no todos los atributos indeseables son tema de discusión, sino únicamente aquellos que son incongruentes con nuestro estereotipo acerca de cómo debe ser determinada especie de individuos" (Goffman; 1998: 13).

En la vida social occidental, las personas homosexuales se ven enmarcadas en categorías y atributos que las encasillan en un estereotipo de sujeto, correspondiendo a lo denominado por Goffman como "identidad social virtual". Esta identidad suele constituirse en un estigma, en la medida que los atributos establecidos constituyen motivo de repudio social.

El estigma, Goffman (1998) lo asocia a un atributo profundamente desacreditador para una persona y señala que "es, pues, realmente, una clase especial de relación entre atributo y estereotipo" (Goffman 1998: 14). Además, el estigma guarda consigo dos matices implícitamente arraigados; que pueden definir a los sujetos portadores como desacreditados o desacreditables. En el primer caso, la calidad de diferente de una persona supone ser conocida por los demás 
en la realidad social y por consiguiente, evidenciada en el acto, como lo son los defectos físicos y/o cualquier otra característica que se puede apreciar en primera instancia, y el segundo matiz, alude a que esa calidad de diferente no es conocida y evidenciada, por cuanto en primera instancia es difícil percibirla. A pesar de que se conceptualizan estas dos dimensiones o matices sobre los estigmas, Goffman señala que "es probable que un individuo estigmatizado en particular haya experimentado ambas situaciones" (Goffman 1998: 14). Ahora bien, en el caso de jóvenes homosexuales existe una alta probabilidad, que ante el rechazo social se muevan en la categoría de desacreditables.

\section{Homosexualidad y encubrimiento}

El encubrimiento, hace referencia a la conducta de ocultamiento y negación de características socialmente estigmatizantes, las que son diversas pero ampliamente compartidas por la sociedad (Arriagada y otros; 2004). Esta conducta se mueve en un continuo entre dos extremos, por un lado, la ignorancia completa del mal estigmatizante, incluyendo al individuo que lo posee, y por otro lado, el estigma que es sutilmente invisible y conocido sólo por el individuo que lo posee. Al respecto Goffman plantea que "es evidente, sin embargo, que estos dos extremos - el conocimiento o la ignorancia totales del estigma- no abarcan un gran número de casos. En primer lugar, existen estigmas importantes, tales como la prostitución, el robo, la homosexualidad, la mendicidad y la adicción a las drogas, que el individuo debe ocultar cuidadosamente ante determinada clase de personas. En segundo lugar, aun en el caso de que un individuo pudiera mantener en secreto un estigma no manifiesto, descubrirá que las relaciones íntimas con los demás, ratificadas en nuestra sociedad por la confesión mutua de defectos invisibles, lo llevan a confesar su situación a los más allegados o a sentirse culpable si no lo hace" (Goffman 1998: 91-92).

\section{Metodología}

La presente investigación constituye un estudio de caso, basado en un enfoque fenomenológico, con un diseño de investigación de carácter cualitativo. A partir de un estudio descriptivo, se recogen las significaciones que los adultos que ejercen el rol parental, le otorgan al ejercicio del rol y a las expectativas respecto del mismo, con posterioridad a la revelación de homosexualidad del joven. La información obtenida en la presente investigación, se recolectó a través de entrevistas semiestructuradas en profundidad. 
Para esta investigación se consideró una muestra no probabilística e intencionada, para la cual se seleccionaron cinco adultos que cumplen el rol parental ${ }^{4}$ respecto de jóvenes homosexuales universitarios de la Región de la Araucanía, quienes reconocen su identidad sexual.

El análisis de los datos obtenidos en el proceso de investigación, se realizó según la Grounded Theory. En este sentido, el procedimiento analítico espera no sólo ser una descripción de datos, sino que involucre un análisis interpretativo, reflexivo e intersubjetivo, de modo que a partir de ello, se genere conocimiento desde la experiencia vital particular de los sujetos. Durante el proceso, se utilizó el software Atlas Ti, el cual permite el análisis cualitativo de datos textuales.

Respecto de los criterios éticos de la investigación, cabe mencionar que se realizó la presentación y firma de un consentimiento informado, que explica propósito y alcances del estudio y compromete el manejo confidencial de la identidad de los participantes. Antes de la aplicación de las entrevistas, se les dio a conocer a los sujetos las preguntas contenidas en la entrevista, de modo que conocieran el contenido de la información a recabar y evaluaran la pertinencia de la misma. Finalmente, se entregó un documento con los resultados más relevantes del estudio a los sujetos que participaron de la investigación.

A continuación se presentan los principales resultados obtenidos en este estudio.

\section{Actitudes de los adultos tras la revelación}

Tras la revelación de la identidad homosexual de un hijo, los adultos manifiestan sentimientos de dolor y tristeza, “. . así que... lo viví con un dolorcito (...) no se lo demostré a él, no se lo demostré, pero igual la lloré toda por todo." (Adulto 1). Además plantean que lo vivieron "en el momento preciso, con una pena porque uno nunca esperaba esto" (Adulto 3), no sólo por lo inesperado de la situación para ellos como padres, sino también por la vivencia del joven "con mucha pena porque mi hijo podría estar sufriendo sin que yo lo supiera..." (Adulto 4).

4 Estos adultos fueron todas madres de los jóvenes. Fueron los mismos jóvenes quienes manifestaron que sus madres constituyen los referentes parentales más significativos, con quienes mantienen una relación más cercana y un vínculo de confianza, respecto de su homosexualidad y las implicancias para sus vidas y relaciones. 
Por otra parte, los adultos intuyen la necesidad de los jóvenes por revelar su verdadera identidad sexual “...quería contarme él a mí, porque ya se iba a sacar todas esas ataduras, to'o... (...) porque 'onde estaba él como que quería contar y... cómo salir ya de ese problema..." (Adulto 1). Igualmente argumentan que "...él lo andaba buscando, si el estaba pidiendo ayuda para llegar a mí, después que yo lo presioné, porque él de vuelta de vacaciones tenía que llevar la respuesta, cómo le había ido conmigo..." (Adulto 4).

Se producen distintas actitudes tras la revelación, pues de algún modo se pone en juego la incondicionalidad del afecto en la relación parental: "él siempre ha tenido el apoyo mío, siempre, pase lo que pase yo siempre ahí levantándole el animo... no, hijo, usted tiene su casa, usted es una persona importante... dándole ánimo..." (Adulto 1). Ello además se refuerza en que "...mi hijo tal vez me necesita en esto... me necesita y ahí me va a tener siempre... entonces yo tengo que entregarle mucho apoyo, estar siempre con él... que él se sienta querido, que se sienta aceptado (...) que no se sienta avergonzado, que yo lo voy a aceptar como es... que yo siempre voy a estar cerca de él, que yo lo voy a apoyar en todo..." (Adulto 2). Este apoyo de los adultos refleja la importancia del vínculo parentofilial. “... una aceptación pero al mil por ciento, no sentí ni un poco de rechazo (...) yo le decía que no me dé explicaciones... que no las necesito, las cosas si son así tienen que ser así (...) yo le dije: no hay nada que perdonar..." (Adulto 2). Ello además se reafirma en que "...como uno es mamá tiene que aceptar a sus hijos como son, de la forma que sea, como lleguen a este mundo..." (Adulto 3).

Los cambios que se producen en la relación, a partir de la revelación de la homosexualidad de los jóvenes, radican en una mayor comunicación entre ambos actores, traduciéndose en una desinhibición de los jóvenes frente a los adultos, para confiarles aspectos íntimos de sí mismos, estableciéndose una mayor confianza entre estos: “... entonces yo le busco para hablarle, le digo qué te pasó..." (Adulto 1) Además se plantea que “... esa confianza que yo andaba buscando, que él me la entregara a mí como mamá (...) un cambio que nos permitió acercarnos más y recuperar esa confianza que antes no teníamos..." (Adulto 2). La generación de confianza se expresa en que "... me puse como en su lugar, oye pero tú no tenî pareja, no te gusta alguien, me ponía en el caso de él, yo a su edad pinchaba y esto y lo otro, para que él se soltara y me fuera contando..." (Adulto 4). 


\section{Preocupaciones de los adultos respecto de la identidad homosexual}

Una preocupación de parte de los adultos, es que la familia extensa no acepte la homosexualidad de los jóvenes, siendo discriminados y alejados del circulo familiar extenso “...porque la familia nunca apoyó cien por ciento, son más lejanos, siempre el círculo de la familia es los que estamos juntos ahora..." (Adulto 2). Ello se refleja además en que: "mi mamá lo aceptaría, su otra abuela no, la familia de parte de su papá, no; a lo mejor hay tíos de parte mía que a lo mejor lo pueden aceptar (...) no, porque yo sé la reacción que van a tener, cómo te dijera, no me van a cerrar las puertas, pero lo van a mirar con indiferencia, como un bicho raro..." (Adulto 3). Otro informante argumenta que: "Yo puedo decir que a lo mejor no lo aceptan, porque en algunas oportunidades ha sido como un rechazo de algunos tíos..." (Adulto 5). Esta discriminación, se traduciría en mofas, burlas y risas, siendo estas prácticas cotidianas en el grupo familiar: "porque por la ignorancia mía, de que yo por ejemplo, o sea así vulgarmente digámoslo: oye pero mira a ese que "se le quema el arroz", ¡o qué sé yo! Si uno por eso uno es que comete muchos errores (...) y uno tiene mucho cuidado después, porque honestamente, si yo no estuviera viviendo esto y mis hijos, yo le diría a mi otro hijo, oye no te juntes con ese porque ese es ihueco!... porque asi hablamos, sin que vivamos la situación que yo vivo..." (Adulto 4). La discriminación se expresa además en que "...hay otras personas que siendo gay, tienen otra manera de hablar, más fina..." (Adulto 5).

Por otro lado, para los adultos existe una clara asociación entre homosexualidad y riesgo de contraer enfermedades venéreas “... claro igual me duele que le pueda pasar algo, igual me preocupo de él, como te dijera, tantas cosas que pasan, hay más enfermedades (...) jamás lo quiero ver enfermo, que eso es lo que sería el dolor más grande, cómo te dijera, y eso sería la parte más difícil: alguna enfermedad..." (Adulto 3). Ello también se plasma en el siguiente relato: "Porque, por temor a una enfermedad, por temor a la oportunidad porque para él es difícil tener una pareja y si fue a una disco (...) entonces a lo que yo voy, a la enfermedad, porque ellos pueden estar muy concientes y ser responsables, pero si tuvieron la oportunidad la aprovecharon nomás, porque no me puede negar que va a ser así, es así (...), si a él le va a costar más, por eso." (Adulto 4).

Otra preocupación de los adultos dice relación con la posibilidad de que los jóvenes terminen sus estudios exitosamente y logren insertarse en el mundo laboral sin sufrir discriminación “... que saque sus estudios, que termine sus estudios, ojala estudie una carrera mi hijo, no estuviera siempre de vendedor... termine sus estudios, hijo, le digo yo..." 
(Adulto 1). Además espera que “... como en todo trabajo, que sea bueno, que lo entiendan, que lo apoyen, que no lo discriminen (...) bueno en el fondo todo puede ser un rechazo, un rechazo por su condición, un rechazo laboral, también puede ser criticado y eso más que nada (...) porque hay gente que si se llegan a enterar o darse cuenta de la condición de él, lo pueden molestar, lo van a fregar, puede haber una reacción..." (Adulto 5).

Sin embargo, manifiestan la esperanza de que la mayor apertura que ha ido surgiendo sobre el tema, permita a sus hijos relacionarse sin ocultar su verdadera identidad sexual: “... si él tiene que ser como es no más... si no se va a poner un cartel atrás no más po'... él tiene que estar como es no más..." (Adulto 1). Otro informante argumenta que: "... debería no avergonzarse y no por el hecho de que yo hable de mi hijo, sino que yo hablo en general..." (Adulto 2). Esta esperanza de no discriminación se plasma en que: “. . ya no es un tabú, ya todo está saliendo más, como te dijera, la mayoría de la gente ya sabe, ya reconoce que una persona es así..." (Adulto 3). Igualmente se plantea que: "... no tanto como revelarlo sino que si en algún minuto le preguntan, sí, soy homosexual..." (Adulto 4).

\section{Expectativas de los adultos acerca de los roles de los jóvenes en el plano de conformación de familia homosexual}

Los adultos consideran relevante que los jóvenes establezcan relaciones de pareja, estables y significativas, donde obtengan apoyo, comprensión y respeto. Connotan el valor de la fidelidad y la relevancia de una buena comunicación entre la pareja: “... que sea buena, que lo quieran, que lo comprendan, así como yo comprendí a mi hijo (...) pa' que lo lleguen a querer bien, que se demuestre tal como es no más... que lo quieran, que se apoyen..." (Adulto 1). Igualmente se argumenta que: "... que se quisieran y que se comprendan, eso sería lo único, que se quisieran ambos, porque hay parejas que están años juntos..." (Adulto 3). Además se espera “... que se respeten mucho y que hubiera mucha lealtad y ser fiel uno con el otro... o sea es transversal esa situación, claro, que tengan un respeto mutuo...que se apoyen y que sea algo de verdad po', que no sea por una semana y chao..." (Adulto 4).

Lo anterior facilitaría una segunda expectativa, que dice relación con la conformación de una familia por parte de los jóvenes, la cual es conceptualizada por los adultos como no tradicional, sino que bipersonal, con los valores tradicionales esperados en una familia occidental "... porque no va a conformar una familia como cualquier otra familia po'... va a ser una familia de a dos (...) que haya 
respeto, que haya cariño..." (Adulto 2). Conjuntamente se espera “... que ojala pueda formar una familia, para que sepa lo que es tener una familia (...); lo que pasa es que uno puede definir esa respuesta de que sea una familia bien constituida, que sea trabajadora, que sean respetuosos, en el fondo que sea una familia buena..." (Adulto 5).

En relación a lo anterior, los adultos no tienen expectativas con respecto a la descendencia intergeneracional de los jóvenes. “... yo pensaba que mi hijo mayor me iba a dar un nieto, como que ahí como que me bajonié un poco, pero de ahí dije... si total el mundo está lleno de estos chicos..." (Adulto 1). La convicción de ello se refleja en que: “... porque más allá no voy a esperar que tenga un hijo po'..." (Adulto 2).

\section{Análisis y discusión}

El momento de revelación de la identidad homosexual de un hijo, constituye un evento de profunda significación en la relación parento-filial. Esta se produce, en tanto ha existido en las figuras parentales la capacidad de acogida necesaria para la revelación del secreto. La identidad homosexual es descubierta y aceptada por los jóvenes de manera paulatina y las figuras parentales logran comprender el encubrimiento inicial, en tanto reconocen el estigma social que rodea a la homosexualidad y las dificultades que conlleva su aceptación. Los adultos reportan vivir este momento con mucho dolor, en primer lugar porque no estaba dentro de sus expectativas que su hijo tuviera una identidad homosexual, y en segundo lugar, puesto que perciben el sufrimiento que ha significado para los jóvenes guardar este secreto ante personas tan significativas como lo son sus figuras parentales. De este modo, vemos que los adultos que ejercen el rol parental no se encuentran preparados para asumir la identidad homosexual de un hijo, puesto que "las huellas de la sociedad" que plantea Goffman, se encuentran fuertemente inscritas en el psiquismo de los adultos, asociando la identidad homosexual a una serie de atributos y estereotipos que ponen en jaque la capacidad de cumplir con el mandato social de enseñarles a protegerse adecuadamente (Linares; 2002).

En este mismo sentido, los adultos temen el rechazo de que puedan ser objeto sus hijos. Respecto de la familia extensa, reconocen la condición de desacreditables que caracteriza al estigma de que son objeto las personas homosexuales, identificando prácticas cotidianas de discriminación y atribución, que se dan al interior de la familia extensa. Esta es una situación compleja, puesto 
que como plantea Pérez (2005), la homosexualidad trasciende la sola conducta sexual, en tanto afecta la filiación humana y el parentesco. Además, el temor de los adultos puede inhibir la revelación de la identidad homosexual a la familia extensa, lo que inevitablemente implicará un distanciamiento de los jóvenes respecto de ésta, en la medida que el secreto impide una reelaboración de los estereotipos que la familia extensa ha construido y comparte respecto de las personas homosexuales, y las prácticas de discriminación y menoscabo asociados a este universo simbólico.

La reconstrucción del universo simbólico asociado a las personas homosexuales es una ardua tarea para las figuras parentales. Los adultos asocian las relaciones homosexuales con un mayor riesgo de contagio de enfermedades venéreas, considerando que la menor probabilidad de encontrar una pareja del mismo sexo, puede incidir en una conducta promiscua.

Respecto de las expectativas que las figuras parentales tienen sobre la vida adulta de los jóvenes homosexuales, una vez que estos se incorporen al ámbito laboral, están atravesadas por el temor a la discriminación de que puedan ser objeto; sin embargo, consideran importante que los jóvenes eviten el encubrimiento y la negación de la identidad homosexual, percibiendo que paulatinamente va aumentando en la sociedad la aceptación hacia las personas homosexuales. En este sentido, los adultos aprueban que en la vida adulta, los jóvenes puedan ir dejando atrás aquella "identidad social virtual”, para construir a través de la experiencia de interacción con otros una "identidad social real" desprovista de prejuicios (Goffman; 1998).

En cuanto a la expectativa de que los jóvenes formen una familia en el futuro, los adultos le otorgan a la relación de pareja estable la categoría de familia, es decir, hay un reconocimiento a la familia bipersonal, sin embargo, la posibilidad del ejercicio parental por parte de los jóvenes, está absolutamente ausente en los relatos de las figuras parentales, descartando de plano la posibilidad de descendencia y/o de adopción, en el evento que la legislación lo permitiera.

\section{Referencias bibliográficas}

ARRIAGADA, D.; BASCUR, A.; SMITH, P.; Y TIZNADO, M. (2004). Representaciones sociales de personas homosexuales residentes en Temuco sobre su interacción social. Memoria para 
optar al título de Trabajador Social, Escuela de Trabajo Social, Universidad Católica de Temuco, Temuco, Chile.

BERGER, L E LUCKMANN, T. (1994). La construcción social de la realidad. Buenos Aires. Amorrortu.

GOFFMAN, E. (1998). Estigma. La Identidad deteriorada. Buenos Aires. Amorrortu.

HERRERA, O. F., No 22. Vol. 2. (2007, Septiembre 10). Construcción de la Identidad Lésbica en Santiago de Chile. Revista UNIVERSUM, Universidad de Talca. Pp. 156 a 168. Disponible en http://universum.utalca.cl/ contenido/index-07-2/art9.pdf

ITURRIETA S. (2001). Perspectivas Teóricas de las Familias: como interacción, como sistemas y como construcción social. Extracto del libro de la autora "Conflictos Familiares ¿Cómo resolverlos?”. CED, Universidad Católica del Norte.

LINARES, J.L. (2002). Del Abuso y Otros Desmanes. Editorial PAIDÓS. Barcelona. España.

MARTIN, C (2002). La parentalidad: Controversias en torno a un problema público. Consultado en marzo de 2010. Disponible en: www.publicaciones.cucsh.udg.mx/pperiod/ laventan/ventana22/7-34.pdf.

MONTEJO REDONDO, O. (2000). Parentalidad Conyugalidad y Nuevos Modelos Familiares. Consultado en enero de 2010. Disponible en: www.avntf-evntf.com/imagenes/ biblioteca/Montejo,\%200.\%20Trab.\%203\%20 BI\%2004-05.pdf

PÉREZ, SANCHO, B. (2004). Homosexualidad: Secreto de Familia. Madrid. Editorial Egales.

PINCUS, L.; DARE, C. (1982). Secretos en la familia. Santiago: Editorial Cuatro Vientos.

SCHUTZ, A. (1993). La construcción significativa del mundo social. Introducción a la sociología comprensiva. Paidós. 